\title{
Apparent amino acid absorption from feather meal by chicks*
}

\author{
BY RACHEL BIELORAI, Z. HARDUF, B. IOSIF \\ AND EUGENIA ALUMOT \\ Division of Animal Nutrition, Institute of Animal Science, Agricultural Research \\ Organization, The Volcani Center, Bet Dagan 50250, Israel
}

(Received 9 August 1982 - Accepted 22 November 1982)

\begin{abstract}
1. The apparent absorption values of individual amino acids from two samples of feather meal (FM) were determined in the lower ileum of chicks fed on diets containing magnesium ferrite as a marker.

2. The average absorption values for FM amino acids were low, approximately 0.50 , as compared with approximately 0.85 for soya bean, used as a control. Values for individual amino acids from FM differed distinctly, ranging from 0.20 to 0.70 . Low values were obtained for aspartic acid, histidine, lysine, glutamic acid and cystine.

3. An indication of the low absorption of the previously-mentioned amino acids was obtained by analysing the amino acid composition of the FM residues undigested by pepsin or pancreatin.

4. The reasons for testing the apparent rather than the true absorption are discussed.
\end{abstract}

In previous work (Bielorai et al. 1982; Neumark et al. 1982) the digestibility of nitrogen from feather meal (FM) by chicks was found to be 0.55 . This value was verified by growth experiments up to 3 weeks of age, confirming the assumption that the absorption of $\mathrm{N}$ reflected protein digestion (Bielorai et al. 1982). This low value for protein digestibility might represent an average of the different liberation rates of various small peptides (Matthews, 1975 ) and in this case the estimation of protein digestibility from $\mathrm{N}$ absorption would not be adequate. The relative absorption rates of the individual amino acids and the extent to which this represents a balanced diet would have to be determined.

Burgos et al. (1974) obtained high values for the true availability of amino acids from FM. These values are in contrast to the low value of 0.55 for total $\mathrm{N}$ absorption from FM obtained in our experiments and to the poor growth of chicks fed on balanced diets containing FM $(150 \mathrm{~g} / \mathrm{kg})$, when a value of 0.85 for $\mathrm{N}$ absorption was assumed (Bielorai et al. 1982).

In the present study, apparent absorption of individual amino acids was determined in the lower ileum of chicks. An attempt was made to find an in vitro digestion method which would reflect the amino acid absorption.

\section{METHODS}

Animals and diets

White Rock chicks (1-d-old) were housed in electrically-heated battery brooders. The chicks were fed on commercial diets for $10 \mathrm{~d}$, then divided into groups of twelve on the basis of equal weights, and fed on a semi-synthetic diet (Table 1) for $6 \mathrm{~d}$. The experimental diets contained 100 or $200 \mathrm{~g} \mathrm{FM} / \mathrm{kg}$ at the expense of glucose. FM was provided as either FM1 (slaughter-house waste), processed at $40 \mathrm{psi}$ for $50 \mathrm{~min}$; or FM4 (Canadian), processed at $100 \mathrm{psi}$ for $3 \mathrm{~min}$.

The magnesium ferrite marker was introduced into the diets as described previously (Neumark et al. 1982).

* Contribution from the Agricultural Research Organization, The Volcani Center, Bet Dagan, Israel. no. 386-E, 1982 series. 
Table 1. Expts 1 and 2. Composition of the semi-synthetic diets $(\mathrm{g} / \mathrm{kg})$

\begin{tabular}{lrrr}
\hline \hline Components & Control & \multicolumn{2}{c}{ Experimental } \\
\hline Feather meal & - & 100 & 200 \\
Soya-bean meal & 470 & 470 & 470 \\
Glucose & 444 & 344 & 244 \\
Constant ingredients* & 86 & 86 & 86 \\
Crude protein $(\mathrm{N} \times 6 \cdot 25)$ & 200 & 270 & 350 \\
$\quad$ Feather meal 1 + , Expt 1 & 212 & 286 & 356 \\
Feather meal 4†, Expt 2 & & & \\
\hline
\end{tabular}

* Constant ingredients $(\mathrm{g} / \mathrm{kg})$ : soya-bean oil 30 , choline chloride, $(500 \mathrm{~g} / \mathrm{kg}$ ) 2 , vitamin mixture (Hurwitz et al. 1967) $2 \cdot 5$, with the addition of $37 \cdot 5 \mu \mathrm{g}$ cholecalciferol $/ \mathrm{kg}$, trace minerals (Hurwitz et al. 1967) 3, sodium chloride 3, calcium carbonate 10, dicalcium phosphate 23 .

$\dagger$ For details, see p. 395.

\section{Analytical methods}

Details of the procedures and compositions of the FM samples are given in previous work (Bielorai et al. 1982).

The amino acids were determined in the freeze-dried contents of the lower ileum, collected in experiments using FM1 and FM4 (Bielorai et al. 1982).

The apparent absorption of each amino acid was calculated by comparing values for amino acid: marker in the diet and the ileal contents (Bielorai et al. 1977) from the equation:

$$
X=1-\left(\frac{A A_{\mathrm{i}}}{\text { marker }_{\mathbf{i}}} / \frac{A A_{\mathrm{f}}}{\text { marker }_{\mathrm{i}}}\right),
$$

where $X$ is the apparent absorption, $A A$ is the concentration of amino acid, $\mathrm{i}$ is the ileum and $f$ is the feed.

The in vitro digestion of FM with pepsin was carried out by the standard method of the Association of Official Analytical Chemists (1970), but with varying pepsin (EC 3.4 .23 . 1) levels of $2,0.2$ and $0.02 \mathrm{~g} / \mathrm{l}$.

The digestion with pancreatin (grade 6, $4 \times$ National Formulary; Sigma Chemical Co., St Louis, Missouri) was carried out by a similar technique, using phosphate-hydrochloric acid buffer, pH 8.2 (Pieniazek et al. 1975) and enzyme concentrations of 2, 0.2 and $0.02 \mathrm{~g} / \mathrm{l}$.

\section{RESULTS}

The absorption values of individual amino acids by chicks fed on FM were distinctly lower than those obtained for soya-bean meal (Table 2). The mean absorption value for soya bean was 0.85 and for the samples of FM1 and FM4 they were 0.55 and 0.48 respectively.

As known from previous work with chicks (Bielorai et al. 1982), the nutritive value of FM4 was slightly inferior to that of FM1. Marked differences were found in the absorption of individual amino acids from FM; especially low values were obtained in both samples for aspartic acid, lysine and histidine and values below the average for cystine and glutamic acid. Although absolute values differed, a similar trend was observed in both FM samples for the absorption of almost all amino acids tested.

The amino acid patterns were determined in the fractions undigested by pepsin or pancreatin in order to test whether some of the less-well absorbed amino acids were more concentrated in these fractions. Although all three enzyme concentrations resulted in a similar pattern of most amino acids, the differences between the undigested fraction and 
Table 2. The apparent absorption of individual amino acids* in chicks fed on two samples of feather meal, FMI and FM4†

(Mean values with their standard errors)

\begin{tabular}{|c|c|c|c|c|c|c|}
\hline \multirow[b]{2}{*}{ Amino acid } & \multicolumn{2}{|c|}{ FM1 } & \multicolumn{2}{|c|}{ FM4 } & \multicolumn{2}{|c|}{$\begin{array}{c}\text { Control } \\
\text { (soya-bean meal) }\end{array}$} \\
\hline & Mean & SE & Mean & $\mathbf{S E}$ & Mean & SE \\
\hline Aspartic acid & 0.37 & 0.05 & 0.28 & 0.07 & 0.82 & 0.01 \\
\hline Threonine & 0.55 & 0.04 & 0.43 & 0.05 & 0.79 & 0.01 \\
\hline Serine & 0.66 & 0.03 & 0.53 & 0.04 & 0.83 & 0.01 \\
\hline Glutamic acid & 0.48 & 0.04 & 0.42 & 0.05 & 0.89 & 0.01 \\
\hline Proline & 0.56 & 0.04 & 0.44 & 0.04 & $0 \cdot 84$ & 0.01 \\
\hline Glycine & 0.63 & 0.03 & 0.55 & 0.05 & $0 \cdot 80$ & 0.03 \\
\hline Alanine & 0.63 & 0.03 & 0.51 & 0.04 & 0.83 & 0.01 \\
\hline Valine & 0.63 & 0.03 & 0.57 & 0.04 & 0.85 & 0.01 \\
\hline Half cystine & 0.52 & 0.05 & 0.40 & 0.07 & $0 \cdot 81$ & 0.02 \\
\hline Methionine & 0.43 & 0.06 & 0.57 & 0.04 & 0.93 & 0.01 \\
\hline Isoleucine & 0.71 & 0.03 & 0.59 & 0.04 & 0.86 & 0.01 \\
\hline Leucine & 0.65 & 0.03 & 0.56 & 0.04 & $0 \cdot 86$ & 0.01 \\
\hline Tyrosine & 0.54 & 0.05 & 0.50 & $0 \cdot 04$ & 0.87 & 0.02 \\
\hline Phenylalanine & 0.67 & 0.04 & 0.59 & 0.04 & 0.85 & 0.02 \\
\hline Lysine & 0.39 & 0.08 & 0.31 & 0.07 & $0 \cdot 87$ & 0.01 \\
\hline Histidine & 0.22 & 0.09 & $0 \cdot 36$ & 0.07 & 0.86 & 0.01 \\
\hline Arginine & 0.63 & 0.03 & 0.55 & $0 \cdot 04$ & $0 \cdot 89$ & 0.01 \\
\hline Mean & 0.55 & & 0.48 & & 0.85 & \\
\hline
\end{tabular}

* Each value is the mean of two experiments, three or four pools of three or four chicks in each (Bielorai et al. 1982).

$\dagger$ For details, see p. 395.

the FM protein were most pronounced with $2 \mathrm{~g}$ pepsin $/ 1$ or $0.02 \mathrm{~g}$ pancreatin/l, which resulted in undigested fractions containing 10 or $9 \%$ of total sample amino acids respectively. The results are presented, therefore, for these concentrations only (Table 3).

The ratio, amino acid levels in the undigested residue (relative to the total): corresponding values in FM, was calculated; values under unity reflect a good enzymic digestion of a given amino acid, whereas those above unity indicate a concentration of the amino acid in the undigested fraction.

A relationship was found between the absorption values in the lower ileum and the amino acid concentration in the undigested fraction. The amino acids showing low absorption in vivo were more concentrated in the fraction undigested by the enzymes and vice versa, with the exception of threonine, proline, methionine and tyrosine.

\section{DISCUSSION}

The mean values for the apparent absorption of individual amino acids were 0.55 for FM 1 and 0.48 for FM4. These values were almost identical with those obtained previously for $\mathrm{N}$ absorption: 0.53 and 0.48 for FM 1 and FM4 respectively, which were confirmed in growth experiments (Bielorai et al. 1982). However, distinct differences were observed between absorption values of individual amino acids in FM, the values ranging from $0 \cdot 20$ to $0 \cdot 70$.

The low absorption of two essential amino acids, lysine and histidine, seems important from the nutritional point of view. These two amino acids were concentrated in the residual fraction, obtained by in vitro digestion with pepsin and pancreatin. The composition of the residual fraction corresponds, in general, to the results in vivo; the amino acids concentrated 
Table 3. The ratio, amino acids* (relative to total) in the residue of two samples of feather meal, FM1 and FM4, $\dagger$ undigested by pepsin or pancreatin : corresponding values in the original material

(Mean values and standard deviations)

\begin{tabular}{|c|c|c|c|c|c|c|c|c|}
\hline \multirow[b]{3}{*}{ Amino acid } & \multicolumn{4}{|c|}{ Pepsin $(2 \mathrm{~g} / \mathrm{l})$} & \multicolumn{4}{|c|}{ Pancreatin $(0.02 \mathrm{~g} / \mathrm{l})$} \\
\hline & \multicolumn{2}{|c|}{ FM1 } & \multicolumn{2}{|c|}{ FM4 } & \multicolumn{2}{|c|}{ FM1 } & \multicolumn{2}{|c|}{ FM4 } \\
\hline & Mean & SD & Mean & SD & Mean & SD & Mean & SD \\
\hline Aspartic acid & $1 \cdot 35$ & 0.04 & $1 \cdot 36$ & 0.05 & $1 \cdot 12$ & 0.02 & 1.05 & 0.03 \\
\hline Threonine & $1 \cdot 31$ & 0.02 & $1 \cdot 17$ & 0.02 & $1 \cdot 25$ & 0.04 & $1 \cdot 18$ & 0.04 \\
\hline Serine & 0.84 & 0 & 0.84 & 0.01 & 0.75 & 0.04 & 0.90 & 0.02 \\
\hline Glutamic acid & $1 \cdot 14$ & 0.03 & $1 \cdot 17$ & 0.01 & $1 \cdot 23$ & 0.02 & $1 \cdot 14$ & 0.02 \\
\hline Proline & 1.05 & 0.03 & $1 \cdot 16$ & 0.01 & $1 \cdot 0$ & 0.01 & 1.03 & 0.06 \\
\hline Glycine & 0.71 & 0.01 & 0.73 & 0.01 & 0.69 & 0.03 & 0.86 & 0.01 \\
\hline Alanine & 0.85 & 0.01 & 0.73 & 0 & 0.97 & 0.04 & 0.96 & 0.02 \\
\hline Valine & 0.92 & 0.01 & 0.76 & 0 & 0.97 & 0.01 & 0.95 & 0.01 \\
\hline Half cystine & 1.40 & 0.03 & 1.69 & $0 \cdot 1$ & 1.03 & 0.07 & 1.05 & 0.01 \\
\hline Methionine & $1 \cdot 50$ & 0.05 & $1 \cdot 17$ & 0.06 & 1.74 & 0.34 & 1.42 & 0.12 \\
\hline Isoleucine & 0.75 & 0.01 & 0.56 & 0.03 & 0.93 & 0.04 & 0.92 & 0.02 \\
\hline Leucine & 0.89 & 0.01 & 0.78 & 0.02 & 0.97 & 0.03 & 0.96 & 0.02 \\
\hline Tyrosine & $1 \cdot 29$ & 0.07 & $1 \cdot 31$ & 0.03 & $1 \cdot 21$ & 0.09 & $1 \cdot 10$ & $0 \cdot 12$ \\
\hline Phenylalanine & 0.71 & 0.01 & 0.58 & 0.02 & 0.84 & 0.02 & 0.84 & 0.01 \\
\hline Lysine & $1 \cdot 70$ & 0.02 & 1.53 & 0.09 & $2 \cdot 39$ & $0 \cdot 11$ & $2 \cdot 09$ & 0.08 \\
\hline Histidine & $1 \cdot 50$ & 0.02 & $1 \cdot 25$ & 0.04 & $2 \cdot 20$ & 0.33 & $1 \cdot 38$ & 0.01 \\
\hline Arginine & 0.96 & 0.01 & $1 \cdot 18$ & 0.03 & 0.72 & 0.01 & 0.80 & 0.01 \\
\hline
\end{tabular}

* Each value is the mean of two or three experiments.

$\dagger$ For details, see p. 395.

in the fraction remaining after enzymic digestion in vitro are those less available for the digestion in vivo, with few exceptions.

The in vitro method may serve as an indication of amino acid availability from FM samples, which may differ substantially due to different processing procedures. The apparent absorption values obtained in this work are in contrast to the values of true availability of amino acids from FM, ranging from 0.95 to 0.99 (average 0.97 ), obtained by Burgos et al. (1974).

Apparent absorption, digestion and availability have actually the same meaning when determined from values for feed disappearance along the digestive tract. The 'true' values are obtained, according to Bragg et al. (1969), by taking into account metabolic and endogenous $\mathrm{N}$, as determined in chicks fed on a protein-free diet, after fasting.

A question to be asked is how the digestion of different feeds at various levels may cause the same metabolic and endogenous $\mathbf{N}$ secretions as in fasting or by feeding protein-free diets. Muztar \& Slinger (1981) came to the conclusion that correcting the apparent availability for losses of metabolic and endogenous $\mathbf{N}$ using unfed birds may introduce an artifact and mask real and important differences between feedstuffs. They stated: 'for most purposes apparent amino acid availability values as obtained in conventional (non-fasting) assays would give a better basis for comparing the values of feedstuffs, than could the TAAA (true amino acid availability) values.'

In a recent workshop on methodology of measuring digestibility and absorption of amino acids, Van Es \& Rerat (1980) stated that there are no reliable methods for measuring endogenous secretion for a given ration. It seems that until endogenous $\mathrm{N}$ can be determined 
with certainty in normally-fed chicks, the apparent absorption of amino acids remains a practical criterion for evaluation of protein quality.

The excellent technical assistance of M. Meidler, Ch. Katz, H. Geller and S. Krasner is gratefully acknowledged. This work was partly financed by the Egg and Poultry Marketing Board of Israel.

\section{REFERENCES}

Association of Official Analytical Chemists (1970). Official Methods of Analysis, 11th ed., p. 127. Washington DC: Association of Official Analytical Chemists.

Bielorai, R., Iosif, B., Neumark, H. \& Alumot, E. (1982). J. Nutr. 112, 249.

Bielorai, R., Tamir, M. \& Hurwitz, S. (1977). J. Nutr. 107, 1775.

Bragg, D. B., Ivy, C. A. \& Stephenson, E. L. (1969). Poult. Sci. 48, 2135.

Burgos, A., Floyd, J. I. \& Stephenson, E. L. (1974). Poult. Sci. 53, 198.

Hurwitz, S., Harrison, H. C. \& Harrison, H. E. (1967). J. Nutr. 91, 319.

Matthews, D. M. (1975). Physiol. Rev. 55, 537.

Muztar, A. J. \& Slinger, S. J. (1981). Poult. Sci. 60, 790.

Neumark, H., Bielorai, R. \& Iosif, B. (1982). J. Nutr. 112, 387.

Pieniazek, D., Rakowska, M., Szkilladziowa, W. \& Grabarek, Z. (1975). Br. J. Nutr. 34, 175.

Van Es, A. J. H. \& Rerat, A. (1980). Proceedings of 3rd EAAP Symposium on Protein Metabolism and Nutrition, publication no. 27, vol. 3, p. 32 [H. J. Oslage and K. Rohr, editors]. Braun, West Germany; European Association of Animal Production. 